\title{
Brontostoma bahiensis sp. nov. de Ectrichodiinae (Hemiptera, Heteroptera, Reduviidae) do Estado da Bahia, Brasil
}

\author{
Hélcio R. Gil-Santana ${ }^{1}$, Luiz A.A. Costa $^{2} \&$ Oton Meira Marques ${ }^{3}$ \\ ${ }^{1}$ Laboratório de Referência Nacional e Internacional em Taxonomia de Triatomíneos, Departamento de Entomologia, \\ Instituto Oswaldo Cruz. Avenida Brasil 4365, Manguinhos, 21045-900 Rio de Janeiro, Brasil. E-mail: helciogil@uol.com.br \\ ${ }^{2}$ Museu Nacional do Rio de Janeiro, Universidade Federal do Rio de Janeiro. Quinta da Boa Vista, 20940-040 Rio de Janeiro, \\ Brasil. \\ ${ }^{3}$ Departamento de Fitotecnia, Escola de Agronomia, Universidade Federal da Bahia, 44380-000 Cruz das Almas, Bahia, \\ Brasil.E-mail: oton@ufba.br
}

\begin{abstract}
Brontostoma bahiensis sp. nov. of Ectrichodiinae (Hemiptera, Heteroptera, Reduviidae) from the State of Bahia, Brazil. A new species of the genus Brontostoma Kirkaldy, 1904, from the State of Bahia, Brazil, is described.

KEY WORDS. New species.
\end{abstract}

RESUMO. Descreve-se uma nova espécie do gênero Brontostoma Kirkaldy, 1904, do Estado da Bahia, Brasil. PALAVRAS CHAVE. Espécie nova.

A subfamília Ectrichodiinae apresenta atualmente 17 gêneros e 111 espécies nas Américas (Carpintero \& Maldonado Capriles 1996). Dougherty (1995), em revisão recente de Ectrichodiinae do Novo Mundo, relacionou 19 gêneros válidos, alguns em discordância com os aceitos por Carpintero \& Maldonado CAPRILES (1996).

Os dois trabalhos mencionados consideraram válido Brontostoma Kirkaldy, 1904, não diferindo sensivelmente na delimitação morfológica e taxonômica desse gênero. DougHERTY (1995) sintetizou os caracteres atribuídos ao mesmo, os quais foram tratados com maior extensão por CARPINTERO \& MALDONADO CAPRILES (1996).

STÅL (1859) criou o gênero Mindarus. Por estar pré-ocupado por Mindarus Koch, 1857 (Hemiptera-Sternorrhyncha: Aphidoidea: Mindaridae), foi substituído por Brontostoma por KirKALDy (1904)

A espécie-tipo do gênero, Ectrychotes discus Burmeister, 1835, foi fixada por designação subseqüente de WygodzinsKY (1949).

As espécies descritas anteriormente à criação do gênero por STÅL (1859), e nele incluídas atualmente, são (com a atual nomenclatura): $B$. discus (Burmeister, 1835), B. haematodes (Blanchard, 1846) e B. rubrum (Amyot \& Serville, 1843). Ressalte-se que B. rubrum, quando descrito por Amyot \& Serville (1843) como Ectrichodia rubra, foi citada como procedente de Java. Embora Wygodzinsky (1949) tenha registrado a inexatidão dessa observação, referindo ser a espécie comum no Brasil,
STÅL (1872) já referia a espécie para "Brasilia [ = Brasil], Bahia", baseando-se em exemplares do Museu de Estocolmo.

Oito espécies atualmente válidas e incluídas em Brontostoma foram descritas por esse último autor: B. alboannulatum (Stål, 1860), B. basalis (Stål, 1859), B. circumductum (Stål, 1859), B. fraternum (Stål, 1859), B. notatum (Stål, 1859), B. rubrovenosum (Stål, 1860), B. sanguinosum (Stål, 1872) e B. trux (Stål, 1859) (STÅL 1859, 1860,1872, Wygodzinsky 1949, 1951, MaldonaDo CAPriles 1990).

Até o início do século XX, foram descritas: B. colossus (Distant, 1902), B. decolor (Walker, 1873), B. pallitarsis (Walker, 1873) e B. rufonotatum (Champion, 1899) (WygodzINSKy 1949, 1951, Maldonado Capriles 1990).

Wygodzinsky (1951) descreveu: B. infensum, B. oglobini oglobini, B. oglobini minor; neste mesmo trabalho, B. haematodes (Blanchard, 1846) foi considerada sinônimo júnior de $B$. discus.

Carpintero (1980), além de descrever B. abbas, B. arlequin, B. castaneus, B. cicheroi, B. discus nigricans, B. lilloi, B. mazzai e $B$. nanus, considerou $B$. decolor (Walker, 1873) sinônimo júnior de B. rubrum.

Atualmente, a maioria das espécies acima citadas são as reconhecidas no gênero. Porém, os últimos autores a tratar de Brontostoma divergem sobre o assunto. Maldonado Capriles (1990) considerou $B$. decolor e $B$. haematodes espécies válidas.

Dougherty (1995), suprimiu B. alboannulatum, B. decolor, $B$. haematodes, B. pallitarsis e as subespécies B. oglobini minor e B. discus nigricans. 
Brontostoma é exclusivamente Neotropical, com a maioria das espécies habitando a América do Sul (CHAmpion 1899, Wygodzinsky 1949, 1951, Maldonado Capriles 1990, Dougherty 1995).

O gênero está representado desde o norte, na Nicarágua (B. rufonotatum) e Panamá (B. sanguinosum) estendendo-se para o sul até o Uruguai e Argentina (CARPINTERo \& Maldonado Capriles 1996). O maior número de espécies ocorre na Argentina, Brasil e Uruguai (Carpintero \& Maldonado Capriles 1996). Dougherty (1995) listou a distribuição geográfica das espécies. As espécies de hábitos já observados alimentam-se em miriápodes e isópodos. A sua picada é muito dolorosa e é usualmente seguida por inflamação e paresia (CARpintero \& Maldonado Capriles 1996).

Apresenta-se a seguir, uma chave para as espécies de Brontostoma do Brasil, baseada na de Wygodzinsky (1951).

\section{Chave para as espécies de Brontostoma do Brasil}

1. Coloração do corpo negra, com marcações amareladas no conexivo e formando faixas ao longo das nervuras principais do cório B. bahiensis sp. nov.

1'. Coloração geral do corpo diferente ..... ... 2

2. Lobo anterior do pronoto de colorido escuro uniforme ... 3

2 '. Lobo anterior do pronoto total ou parcialmente avermelhado ... 5

3. Lobo posterior do pronoto inteiramente avermelhado. Cório avermelhado com uma mancha escura longitudinal central infensum

3'. Lobo posterior do pronoto com mais de uma cor. Cório negro ou bem escurecido ...

4. Cório enegrecido, com manchas vermelhas, a maior na base e duas menores na base da membrana. Região pleural do tórax com cerca de cinco manchas vermelhas ... fraternum

4'. Cório negro a bem escurecido, com duas a quatro faixas longitudinais vermelhas, que podem ser acompanhadas por faixas transversais entre as mesmas. Região pleural avermelhada ou escurecida .................................... colossus

5. Cório amarelo ou vermelho, sem marcações ...................... 6

5'.Cório negro, com marcações vermelhas ou amarelas de extensão variada ..... 7

6. Espaço interocular do macho medindo até uma vez e meia a largura do olho; o da fêmea até duas vezes esse valor. Antena do macho com numerosos pêlos longos, incluindo os segmentos basais ...... oglobini

6'. Espaço interocular do macho medindo duas vezes a largura do olho; o da fêmea mais que duas vezes esse valor. Segmentos basais da antena do macho sem pêlos ....... rubrum

7. Pronoto vermelho, o lobo posterior geralmente apresenta uma grande mancha central enegrecida, que pode estar dividida em duas menores ou estar ausente. Cório negro com uma faixa longitudinal estreita, a qual pode ser quase imperceptível discus
7'. Sem essa combinação de caracteres .... 8

8. Pronoto vermelho ou avermelhado, sem manchas. Hemiélitros negros, com base avermelhada circumductum

8'. O pronoto pode ter manchas ou faixas escurecidas. Hemiélitros escurecidos com marcações avermelhadas ao longo do cório...

9. Fêmures medianos muito fortes, possuindo uma conspícua saliência ventral submediana . colossus

9'. Fêmures medianos relativamente delicados, sem saliência ventral 10

10. Conexivo escuro, com o bordo externo amarelo. Regiões vermelhas do cório mais extensas que as enegrecidas ....... alboannulatum

10'. Conexivo com manchas claras e escuras alternadas. Regiões escuras do cório mais extensas que as vermelhas ........ rubrovenosum

\section{Brontostoma bahiensis sp. nov. Figs $1-4$}

Descrição (dimensões em milímetros). Fêmea. Corpo: comprimento: 24. Cabeça: comprimento: 3,6; largura total (incluindo os olhos): 2,6; largura entre os olhos: 1,3 ; antena: segmento I: 2,7 ; segmento II: 3,2 ; segmento III: 1,5 ; segmento IV: 1,0; segmento V: 0,8; segmento VI: 0,3; segmento VII: 0,8; comprimento total do rostro: 4,8 ; segmento I: 2,5 ; segmento II: 1,4 ; segmento III: 0,9 . Tórax: lobo anterior do pronoto: comprimento: 2,0; largura: 4,6; lobo posterior do pronoto: comprimento: 2,5; largura: 6,3; comprimento do escutelo: 2,9; largura do escutelo: 3,2 ; comprimento do hemiélitro: 18,1 ; pernas anteriores: fêmur: 4,6; tíbia: 4,6; tarso: 1,2; pernas médias: fêmur: 4,7; tíbia: 5,0; tarso: 1,4; pernas posteriores: fêmur: 7,6; tíbia: 8,0; tarso: 1,8. Abdome: comprimento: 15,0; largura: 8,0.

Superfície corporal lisa e glabra, com pêlos longos, curtos e finos a partir da metade do segundo segmento antenal e nos $2 / 3$ apicais das faces internas das tíbias e nos tarsos.

Cabeça (Figs 1-4). Subalongada, olhos pouco salientes; tubérculo ocelar raso; rostro negro. Antenas com sete segmentos, castanho escura a negra com o terço apical do terceiro ao sexto segmentos amarelos a branco amarelados; no terceiro segmento observa-se, também, um anel escurecido no ápice. $\mathrm{O}$ primeiro segmento antenal glabro; no segundo encontram-se pêlos curtos na face superior de quase todo o segmento e nas demais faces, a partir da metade apical, ao lado de raros pêlos longos. Demais segmentos antenais com pêlos curtos e longos, estes mais esparsos.

Tórax (Figs 1, 2 e 4). Negro, com tegumento brilhoso. Pronoto: sulco transverso bem marcado; no lobo anterior o sulco mediano longitudinal representado por depressão posterior que não alcança o sulco transverso. No lobo posterior, o mesmo tênue e limita-se à metade anterior do segmento. Escutelo com duas pontas curtas e pouco convergentes. Sulco estridulatório levemente mais claro. Pernas: coxas, trocânteres 

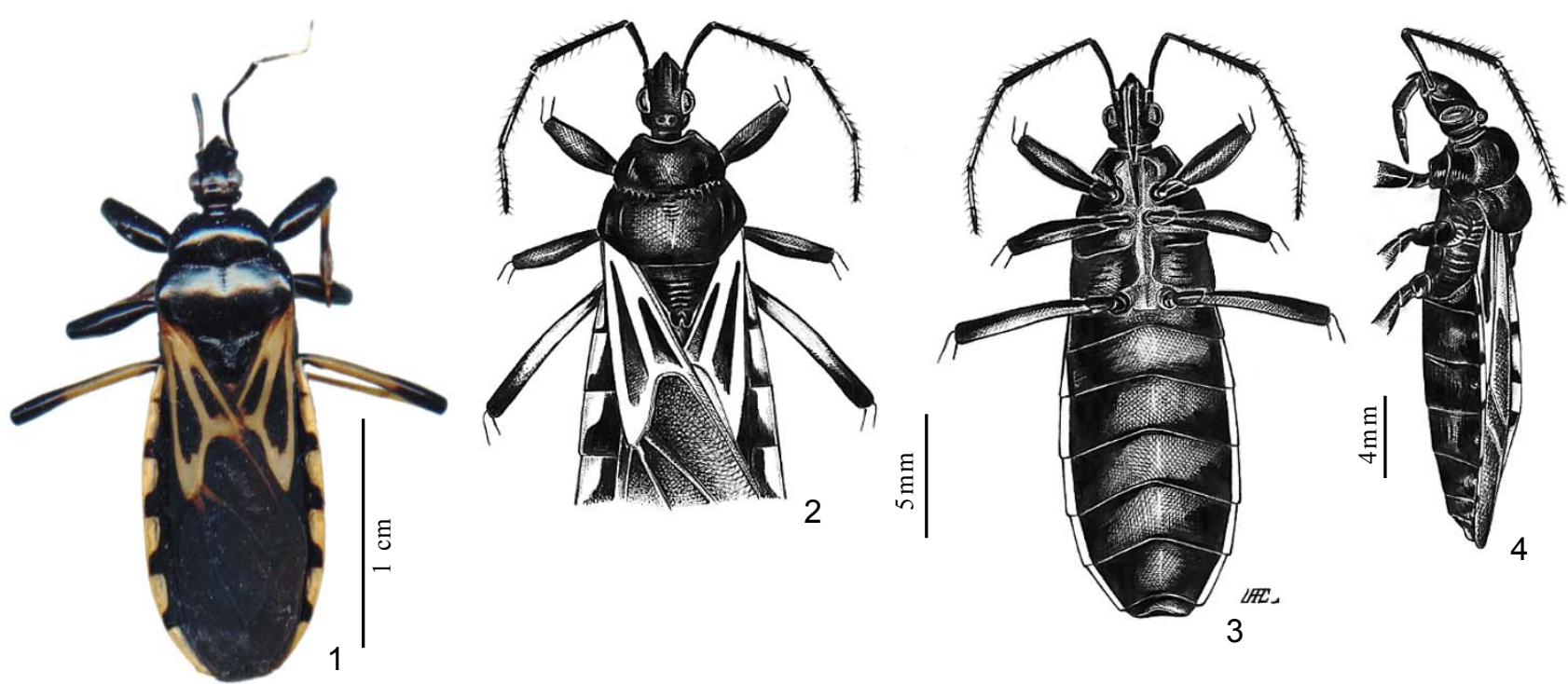

Figuras 1-4. Brontostoma bahiensis sp. nov.: (1) fotografia do holótipo, fêmea, vista dorsal; (2) cabeça, pronoto e cório dos hemiélitros, fêmea, vista dorsal; (3) fêmea, vista ventral; (4) fêmea, vista lateral.

e pleuras bem escurecidas, com tegumento brilhoso. Fêmures enegrecidos, os anteriores bem espessados, os médios menos espessados e os posteriores retilíneos com leve entumescimento pré-apical e apresentando extensa mancha médio-basal amarelada na face superior e outra linear e estreita na face inferior, em posição sub-basal. Tíbias anteriores e médias com fossas esponjosas ocupando cerca de 1/4 do ápice das mesmas, apresentando-se levemente entumescidas na região das fossas esponjosas, nas posteriores há somente um tufo de pêlos dourados no ápice. Tíbias anteriores escurecidas com anel amarelado largo em posição sub-basal, o qual se estende em direção distal nas faces superior e inferior. Tíbias médias amareladas, com a base e a porção apical subjacente à fossa esponjosa enegrecidas. Tíbia posterior amarelada com um anel basal estreito e o extremo apical, enegrecidos. Tarsos trímeros, escurecidos, com a face superior dos dois primeiros segmentos mais claros. Hemiélitros negros, cório apresentando faixas amareladas ao longo das três nervuras principais, formando desenho nítido; na membrana a porção basal das nervuras, em extensão variável, levemente amarelada.

Abdome negro (Fig. 3); conexivo amarelado, com a borda interna dorsal e a metade distal de cada segmento, enegrecidas (Figs 1 e 2). Esternitos negros possuindo tegumento liso com ligeiras rugosidades nas faces laterais (Figs 3 e 4). Segmentos genitais enegrecidos.

Distribuição geográfica: BRASIL, Estado da Bahia, Barro Preto.

Material examinado. Holótipo fêmea. Brasil, Estado da Bahia, Barro Preto (14 43' 10" S - 39 22' 05" W), III.2003, O. M. Marques leg., Coleção Entomológica do Museu Nacional da
Universidade Federal do Rio de Janeiro (MNRJ).

Etimologia. O nome da espécie alusivo ao estado da Bahia, Brasil, no qual o único exemplar conhecido foi coletado.

\section{AGRADECIMENTOS}

Ao Prof. Dr. P.H. van Doesburg Jr., do Rijksmuseum van Natuurlijke Historie, Leiden (Holanda), pelo auxílio na obtenção dos trabalhos de Carl Stål. Ao Biólogo e Heteropterista Dimitri Forero, da Colômbia, pelas observações fornecidas sobre a taxonomia do grupo estudado. Ao Almirante Centro de Estudos de Cacau, pelo financiamento da pesquisa que possibilitou a coleta de Brontostoma bahiensis sp. nov..

\section{REFERÊNCIAS BIBLIOGRÁFICAS}

Амyot, C.J.B. \& A. Serville. 1843. Histoire Naturelle des Insectes. Hémiptères. Paris, Libraire Encyclopedique de Roret. Fain et Thunot, XXVI+675+6p.

Carpintero, D.J. 1980. Nuevos Ectrichodiinae Americanos (Insecta - Hemiptera - Reduviidae). Acta Scientifica, Serie Entomología, Buenos Aires, 14: 3-33.

Carpintero, D. J. \& J. Maldonado-Capriles. 1996. Diagnostic characters and key to the Genera of American Ectrichodiinae (Heteroptera, Reduviidae). Caribbean Journal of Sciencies, Mayagüez, 32 (2): 125-141.

Champion, G.C. 1899. Insecta Rhynchota. HemipteraHeteroptera, p. 229-243. In: F.D. Godman \& O. SAlvin (Eds). Biologia Centrali Americana. Rhynchota. London, vol. 2, XIV+416p.

DougherTy, V. 1995. A review of the New World Ectrichodiinae 
Genera (Hemiptera: Reduviidae). Transactions of the American Entomological Society, Philadelphia, 121 (4): 173-225.

KIRKALDY, G.W. 1904. Bibliographical and nomenclatorial notes on the Hemiptera. Entomologist, London, 37: 279-283.

Maldonado Capriles, J. 1990. Systematic Catalogue of the Reduviidae of the World (Insecta: Heteroptera). Caribbean Journal of Sciencies, special edition, Mayagüez, 694p.

STÅL, C. 1859. Till kännedomen om Reduvini. Öfversigt af Kongliga Vetenskaps-Akademiens Förhandlingar, Stockholm, 16: 175-204.

. 1860. Bidrag till Rio de Janeiro-traktens Hemipter-

Recebido em 12.VIII.2003; aceito em 24.II.2004. fauna. I. Kongliga Svenska Vetenskaps-Akademiens Handlingar, Stockholm, 2: 1-84.

- 1872. Enumeratio Hemipterorum. Kongliga Svenska Vetenskaps-Akademiens Handlingar, Stockholm, 10: 66-123.

WygodZinsKY, P. 1949. Elenco sistematico de los reduviiformes americanos. Instituto de Medicina Regional de la Universidad Nacional de Tucumán, Monografia, 1: 1-102. . 1951. Notas sobre Ectrichodiinae Neotropicales (Hemipt. Reduviidae). Revista de la Sociedad Entomológica Argentina, Buenos Aires, 15: 35-52.

Revista Brasileira de Zoologia 21 (1): 127-130, março 2004 